\title{
Vitamin D Deficiency/Insufficiency and Anxiety Among Saudis: Degree and Differences
}

\author{
Al Hariri, Ahmed, PhD \\ Associate Professor of Mental Health \\ Taif University, Department of Psychology, Riyadh, Saudi Arabia \\ doi: 10.19044/esj.2016.v12n27p93 URL:http://dx.doi.org/10.19044/esj.2016.v12n27p93
}

\begin{abstract}
Background: Vitamin D deficiency/insufficiency and anxiety are rapidly growing epidemics among Saudis. Objectives: This study aims to explore the degree and rates of anxiety among Saudis with vitamin D deficiency and insufficiency, to investigate the anxiety means differences between males and females with low vitamin D levels, and to investigate the anxiety means differences between the participants of the same gender in each of two groups, those with vitamin D deficiency and those with insufficiency. Methods: A cross-sectional study was carried out on 228 Saudi participants from two medical centres in Riyadh, Saudi Arabia. A structured questionnaire was used to measure anxiety, and the lab analysts at the two centres reported the participants' vitamin D levels based on their blood tests. Results: The anxiety mean among Saudis with vitamin D deficiency was higher than among their peers with vitamin D insufficiency. Significant differences in anxiety means existed between males and females with vitamin D insufficiency by a large magnitude, and between males in both groups, with vitamin D deficiency and insufficiency, by a moderate magnitude. Conclusion: Although Saudi females were higher in their anxiety means in both groups, vitamin D deficiency and insufficiency, both anxiety and low vitamin D levels are continuous problems in Saudi Arabia. Hence, more could be done to foster awareness and to combat these issues through consuming vitamin D supplements and increasing food quality.
\end{abstract}

Keywords: Anxiety; Vitamin D; Deficiency; Insufficiency.

\section{Introduction}

Vitamin D represents vitamin $\mathrm{D}_{2}$ (ergocalciferol), which comes from irradiation of the yeast and plant sterol ergosterol, or refers to vitamin $D_{3}$ (holecalciferol), which can be found in oily fish, cod liver oil, and is also made in the skin when it is exposed to sunlight (Holick, 2006a; Lašaite et al., 
2011). Vitamin D from the skin and diet metabolises in the human liver to become 25-hydroxyvitamin $\mathrm{D}[25(\mathrm{OH}) \mathrm{D}]$ and is used to determine a person's vitamin D level (or status) (Holick, 2006b), which is supposed to be above $30 \mathrm{ng} / \mathrm{mL}$. However, low vitamin D level, deficiency $(\leq 10 \mathrm{ng} / \mathrm{mL})$ and insufficiency $(10.1 \mathrm{ng} / \mathrm{mL}$ to $30 \mathrm{ng} / \mathrm{mL})$, has become a global health problem that some studies consider an epidemic. It poses a risk to and affects peoples' health, both children and adults (Bosomworth, 2011; Faiz, Panunti, \& Andrews, 2007; Goldstein, 2009). For instance, it is related to physical problems such as autoimmune diseases (Holick, 2005), osteoarthritis, diabetes, cardiovascular disease, cancer (Holick, 2007), chronic kidney disease (Kim \& Kim, 2014), and obesity (Johnson et al., 2012). It is also related to mental problems such as mood disorders (Humble, 2010) and depression and anxiety (Al Hariri, 2016; Al Khatib \& Rawashdeh, 2014; Howland, 2011). Vitamin D deficiency/insufficiency is an abundantly clear problem in Saudi Arabia. A number of studies (Elsammak et al., 2011; Hussain et al., 2014; Sadat-Ali et al., 2009) have highlighted that from $28 \%$ to more than $65 \%$ of Saudis, of all ages, suffer from low vitamin D levels. However, vitamin D deficiency and insufficiency are not the only common health problems in Saudi Arabia.

Anxiety, which is a very common mental health condition that affects an individual's daily life and may lead later to psychological disorders (Craske \& Stein, 2016), is another common health issue in Saudi Arabia. It was found that $13.8 \%$ of Saudi outpatients are diagnosed with anxiety disorder (Qureshi et al., 2001), and this disorder is common among Saudis of different ages. For instance, it was found that from $14 \%$ to $14.3 \%$ of high school Saudi students suffer from anxiety (Al Gelban, 2009; Amr, Amin, \& El-Wasify, 2012). However, a higher prevalence of anxiety was found in another research conducted by Al-Gelban, Al-Amri, \& Mostafa (2009) which claimed that $66.2 \%$ of secondary school Saudi girls suffer from anxiety compared with other disorders like stress $(52.5 \%)$ and depression $(41.5 \%)$. Concerning an older age group, Ibrahim et al. (2013) found that $33.3 \%$ of Saudi female medical undergraduates suffer from anxiety. In addition, it was found that phobic anxiety is a common type of anxiety among Saudi females (Al Gelban, 2009), whereas social anxiety disorder is the more common type among Saudi males (Ghazwani, Khalil, \& Ahmed, 2016). Nevertheless, the literature did not investigate if anxiety levels were different among Saudis with low vitamin D levels, i.e. deficiency or insufficiency.

This study aims to explore the degree of anxiety among Saudis with vitamin $\mathrm{D}$ deficiency and insufficiency; to investigate the anxiety differences between Saudi males and females with low vitamin D levels; and also to investigate the anxiety differences between Saudis - from the same gender - 
with vitamin D deficiency and with vitamin D insufficiency. The research questions are:

What is the degree of anxiety among Saudis with vitamin D deficiency and insufficiency?

What is the difference in anxiety rates between Saudi males and females with vitamin $D$ deficiency and insufficiency?

What is the difference in anxiety rates between Saudis - of the same gender - with vitamin $D$ deficiency and their peers with vitamin $D$ insufficiency?

\section{Methodology}

\section{Research Design}

Cross-sectional design was used in this study because it is the most appropriate methodological approach when (a) using a questionnaire to (b) deduct the relationship between two or more variables in (c) a large sample being targeted (Bryman, 2012; Robson, 2011). Regarding the adopted statistics, confirmatory factor analysis - maximum likelihood - and Cronbach's alpha were used to investigate the research instrument quality. Descriptive statistics, e.g. mean $(M)$ and standard deviation $(S D)$, were used in the sample description and in answering the first question. An independent-sample t-test was used to answer the second and third questions to compare the differences in anxiety rates between different groups, i.e. to compare the anxiety means between males and females to answer the second question, and to compare the anxiety means between participants with vitamin D deficiency with their peers with vitamin D insufficiency, from the same gender, to answer the third question.

\section{Sampling}

The targeted sample was made up of Saudi clients who visited two health care centres, Kingdom Hospital and Al-Borg Medical Laboratories both located in Riyadh, Saudi Arabia - during 2015 for regular medical check-ups including blood tests. Approval for this investigation was obtained from the ethics committees of both centres. The laboratory analysts at both centres determined the clients who had a vitamin $D$ deficiency or insufficiency based on their blood test reports, and thus, they were a convenient available sample. In addition, these targeted clients were asked if they consented to participate in this study and then they were asked to complete the questionnaire. At this stage, these participants did not know yet that their vitamin D levels were low. Furthermore, it was taken into consideration that these participants were not suffering from any illnesses and were not using any medication or treatment. In other words, they suffered only from low vitamin D levels. 
Even though some studies, such as (Green et al., 2015), determined that the vitamin $\mathrm{D}$ deficiency range is $\leq 15 \mathrm{ng} / \mathrm{mL}$, while insufficiency ranges between 15 and $20 \mathrm{ng} / \mathrm{mL}$, these cutoff values are debatable (BischoffFerrari, 2007; Modan-Moses et al., 2015; Tuffaha et al., 2015; Whiting \& Calvo, 2005). Hence, the cutoff values that were adopted in this study are the values that both Saudi health centres use, which are: $\leq 10 \mathrm{ng} / \mathrm{mL}$ for vitamin $\mathrm{D}$ deficiency, and between $10.1 \mathrm{ng} / \mathrm{mL}$ and $30 \mathrm{ng} / \mathrm{mL}$ for vitamin $\mathrm{D}$ insufficiency.

The sample comprises 228 participants, of which 115 suffer from vitamin D deficiency and 113 suffer from vitamin D insufficiency. All of them reported their age, with the exception of two females in the vitamin D insufficiency group: therefore, they were not included - only - in the age descriptive statistics of that group. Table 1 shows the descriptive statistics of the sample.

Table 1: Shows descriptive statistics of the sample

\begin{tabular}{|c|c|c|c|c|c|c|}
\hline & \multicolumn{3}{|c|}{ Males } & \multicolumn{3}{|c|}{ Females } \\
\hline & $\mathrm{n}(\%)$ & $\begin{array}{l}\text { Age range } \\
\text { M(SD) }\end{array}$ & $\begin{array}{c}\text { Vitamin } \\
\text { D range } \\
\text { M(SD) }\end{array}$ & $\mathbf{n}(\%)$ & $\begin{array}{l}\text { Age range } \\
\text { M(SD) }\end{array}$ & $\begin{array}{c}\text { Vitamin } \\
\text { D range } \\
\text { M(SD) }\end{array}$ \\
\hline $\begin{array}{l}\text { Vitamin D } \\
\text { Deficiency }\end{array}$ & $64(56 \%)$ & $\begin{array}{c}18-60 \\
33.09(10.4)\end{array}$ & $\begin{array}{c}4.3 \mathrm{ng} / \mathrm{mL} \\
-10 \\
\mathrm{ng} / \mathrm{mL} \\
7.4(1.6)\end{array}$ & $51(44 \%)$ & $\begin{array}{c}14-80 \\
29.8(12.1)\end{array}$ & $\begin{array}{c}3 \mathrm{ng} / \mathrm{mL}- \\
10 \mathrm{ng} / \mathrm{mL} \\
6.8(1.5)\end{array}$ \\
\hline $\begin{array}{c}\text { Vitamin D } \\
\text { Insufficiency }\end{array}$ & $63(56 \%)$ & $\begin{array}{c}20-70 \\
38.6(10.4)\end{array}$ & $\begin{array}{c}10.1 \\
\mathrm{ng} / \mathrm{mL}- \\
28.2 \\
\mathrm{ng} / \mathrm{mL} \\
14.9(4.2)\end{array}$ & $50(44 \%)$ & $\begin{array}{c}20-70 \\
35.7(11.3)\end{array}$ & $\begin{array}{c}10.6 \\
\mathrm{ng} / \mathrm{mL}- \\
27.1 \\
\mathrm{ng} / \mathrm{mL} \\
15.9(4.2)\end{array}$ \\
\hline
\end{tabular}

\section{Research Instrument}

A structured questionnaire was developed by the current researcher to measure anxiety, noting that this tool and its statements was constructed by using DSM-5 (American Psychiatric Association, 2013), ICD-10 (World Health Organization, 1992), and the researcher's experience as a psychotherapist for over 16 years. Arabic was the medium of this instrument because it is the mother tongue of the participants, and a pen-and-paper format was chosen as it produces a higher responses rate than on-line questionnaires do (Cook, Heath, \& Thompson, 2000; Nulty, 2008).

This one-page questionnaire includes a first section about demographical questions (age and sex) and also a question about vitamin D level, which is the only question that was completed by the lab analyst based on the participant's blood test report. After that, the second section includes 14 five-point Likert scale statements measuring anxiety. 
By pursuing Confirmatory Factor Analysis (CFA) - Maximum Likelihood - the validity of this questionnaire was investigated. The CFA outcomes show that $\mathrm{X}^{2}=52.61$, RMSEA $=0.00, \mathrm{GFI}=0.982$, AGFI $=0.979$, $\mathrm{CFI}=1.0, \mathrm{RFI}=0.862, \mathrm{NNFI}=0.882$, and $\mathrm{NFI}=0.873$, which all represent a valid questionnaire. Concerning reliability, the Cronbach's Alpha was $\alpha=0.678$, which is considered as the cutoff of an adequate scale (Shelby, 2011, p. 142).

\section{Results}

1) What is the degree of anxiety among Saudis with vitamin D deficiency and insufficiency?

Descriptive statistics, means $(M)$ and standard deviations $(S D)$, were used to explore the degree of anxiety among Saudis with low vitamin D levels: deficiency and insufficiency. Table 2 illustrates these statistics.

Table 2: Shows descriptive statistics of the degree of anxiety

\begin{tabular}{cccccc}
\hline \multirow{2}{*}{ Anxiety statements } & \multicolumn{2}{c}{ Deficiency group } & \multicolumn{2}{c}{ Insufficiency } \\
& & & group \\
\cline { 2 - 5 } & & SD & M & SD \\
\hline 1 & I feel very nervous and worried & 2.77 & 1.13 & 2.75 & 1.15 \\
\hline 2 & I feel that my heart palpitations are fast & 2.83 & 1.05 & 2.44 & 1.07 \\
\hline 3 & I feel suffocation and shortness of breath & 2.57 & 1.12 & 2.21 & .93 \\
\hline 4 & I feel cold and my face is pale & 3.10 & 1.15 & 2.42 & 1.06 \\
\hline 5 & My chest hurts and I sigh continuously & 2.55 & .98 & 2.40 & 1.08 \\
\hline 6 & I feel my pulse in every part of my body & 2.84 & 1.08 & 2.45 & 1.09 \\
\hline 7 & My muscles are tense and tight & 2.72 & .97 & 2.57 & 1.03 \\
\hline 8 & I always have headaches and feel tired & 2.93 & 1.05 & 2.83 & 1.18 \\
\hline 9 & It is hard for me to control my nervousness & 2.67 & 1.01 & 2.51 & 1.04 \\
\hline 10 & I have appetite problems and I am losing & 2.33 & 1.14 & 1.96 & 1.05 \\
\hline 11 & weight & 2.68 & 1.12 & 2.73 & 1.24 \\
\hline 12 & I am confused and hesitant about everything & 2.43 & 1.00 & 2.50 & 1.18 \\
\hline 13 & I feel fear and expect bad things & 2.32 & 1.10 & 2.43 & 1.30 \\
\hline 14 & I feel dizzy and I will vomit & 2.15 & 1.01 & 2.07 & 1.00 \\
\hline$*$ & Total degree of anxiety & 2.63 & .62 & 2.45 & .70 \\
\hline
\end{tabular}

Table 2 shows that the degree of anxiety among Saudis with vitamin $\mathrm{D}$ deficiency was higher than their peers who suffered from vitamin D insufficiency; that is the anxiety mean for the first group is 2.63 whereas the second group is 2.45. Similar results are shown for each of the anxiety statements, that is the mean of the majority of the statements was higher among Saudis with vitamin D deficiency, with the exception of statements $11,12,13$, and 14 which were slightly lower in the mean among the group with vitamin $\mathrm{D}$ deficiency than their peers in the insufficiency group. In addition, the standard deviation of anxiety, in total, is smaller among clients 
with vitamin D deficiency; and also the majority of the standard deviations of the statements were smaller among this group of participants.

2) What is the difference in anxiety rates between Saudi males and females with vitamin $D$ deficiency and insufficiency?

An independent-sample t-test was used to investigate the differences in rates of anxiety between males and females in each group: Saudis with vitamin D deficiency, and insufficiency. Table 3 illustrates these differences.

Table 3: Shows independent-sample t-test of the rates of anxiety for Saudi males and females with vitamin D deficiency and insufficiency

\begin{tabular}{|c|c|c|c|c|c|c|c|c|}
\hline & Groups & $\mathrm{n}$ & $\mathrm{M}$ & SD & $\mathrm{F}$ & Sig. & $\mathrm{t}$ & Sig. \\
\hline \multirow{2}{*}{$\begin{array}{l}\text { Anxiety among Saudis with } \\
\text { vitamin D deficiency }\end{array}$} & Males & 64 & 2.54 & .60 & \multirow{2}{*}{.03} & \multirow{2}{*}{.85} & & \multirow{2}{*}{.084} \\
\hline & Females & 51 & 2.75 & .63 & & & 1.74 & \\
\hline \multirow{2}{*}{$\begin{array}{l}\text { Anxiety among Saudis with } \\
\text { vitamin D insufficiency }\end{array}$} & Males & 63 & 2.20 & .67 & \multirow{2}{*}{.87} & \multirow{2}{*}{.35} & - & \multirow{2}{*}{$.001 *$} \\
\hline & Females & 50 & 2.77 & .60 & & & 4.72 & \\
\hline
\end{tabular}

As can be seen from Table 3, there was not a significant difference between scores for Saudi males with vitamin D deficiency $(n=64, M=2.54$, $S D=.60)$ and their female peers $(n=51, M=2.75, S D=.63 ; t(113)=-1.74$, $p=.084$, two-tailed). In contrast, and regarding Saudis with vitamin D insufficiency, there was a significant difference between scores for Saudi males with vitamin D insufficiency $(n=63, M=2.20, S D=.67)$ and their female peers $(n=50, M=2.77, S D=.60 ; t(111)=-4.72, p<.001$, two-tailed $)$. The magnitude of the differences in the means (mean difference $=-.57,95 \%$ $C I$ : -.82 to -.33 ) was large (eta squared $=.17$ ).

In addition, the differences between males and females in rates of anxiety, based on the median, in each vitamin D deficiency and insufficiency group, was investigated by using a boxplot, as Figure 1 illustrates.
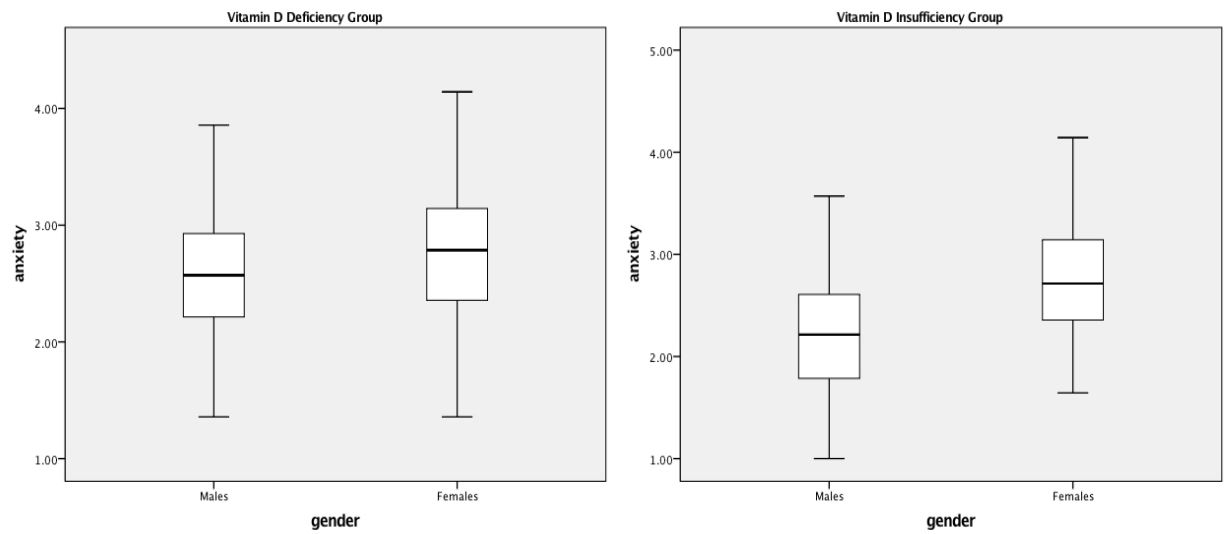

Figure 1: Shows boxplot of the differences in rates of anxiety between Saudi males and females in both groups of vitamin D deficiency and insufficiency 
As can be seen from Figure 1, the anxiety median of Saudi males with vitamin $\mathrm{D}$ deficiency is 2.57 (the upper quartile is 2.93 , the lower quartile is 2.21); whereas the median of their female peers is 2.78 (the upper quartile is 3.14, the lower quartile is 2.28). Concerning Saudis with vitamin $\mathrm{D}$ insufficiency, the males' median of anxiety is 2.21 (the upper quartile is 2.64, the lower quartile is 1.8); while the median of their female peers is 2.71 (the upper quartile is 3.16, the lower quartile is 2.36).

3) What is the difference in anxiety rates between Saudis - from the same gender - with vitamin $D$ deficiency and their peers with vitamin $D$ insufficiency?

An independent-sample t-test was used to investigate the differences in rates of anxiety between Saudis - from the same gender - in each group, the vitamin D deficiency group and the insufficiency group. Table 4 illustrates these differences.

Table 4: Shows independent-sample t-test of anxiety rates for Saudi males with vitamin D deficiency and insufficiency, and Saudi females with vitamin D deficiency and insufficiency

\begin{tabular}{|c|c|c|c|c|c|c|c|c|}
\hline & Groups & $\mathrm{n}$ & $\mathrm{M}$ & SD & $F$ & Sig. & $\mathrm{t}$ & Sig. \\
\hline $\begin{array}{l}\text { Anxiety among Saudis with } \\
\text { vitamin D deficiency }\end{array}$ & Males & 64 & 2.54 & .60 & \multirow{2}{*}{.08} & \multirow{2}{*}{.36} & \multirow{2}{*}{3.11} & \multirow{2}{*}{$.002 *$} \\
\hline $\begin{array}{l}\text { Anxiety among Saudis with } \\
\text { vitamin D insufficiency }\end{array}$ & Males & 63 & 2.20 & .67 & & & & \\
\hline $\begin{array}{l}\text { Anxiety among Saudis with } \\
\text { vitamin D deficiency }\end{array}$ & Females & 51 & 2.75 & .63 & \multirow{2}{*}{.07} & \multirow{2}{*}{.80} & \multirow{2}{*}{-.18} & \multirow{2}{*}{.858} \\
\hline $\begin{array}{l}\text { Anxiety among Saudis with } \\
\text { vitamin D insufficiency }\end{array}$ & Females & 50 & 2.77 & .60 & & & & \\
\hline
\end{tabular}

As can be seen from Table 4, there was significant difference between the scores for Saudi males with vitamin D deficiency $(n=64$, $M=2.54, S D=.60)$ and their peers with vitamin D insufficiency $(n=63$, $M=2.20, S D=.67 ; t(125)=3.11, p<.01$, two-tailed). The magnitude of the differences in the means (mean difference $=.35,95 \% C I: .13$ to .57 ) was moderate (eta squared $=.07$ ). In contrast, regarding the females, there was not a significant difference between the scores for Saudi females with vitamin D deficiency $(n=51, M=2.75, S D=63)$ and their peers with vitamin D insufficiency ( $n=50, M=2.77, S D=.60 ; t(99)=-.18, p=.858$, two-tailed).

In addition, the differences in anxiety rates between Saudis with vitamin D deficiency and insufficiency - from the same gender - based on the median, was investigated by using a boxplot, as Figure 2 illustrates. 

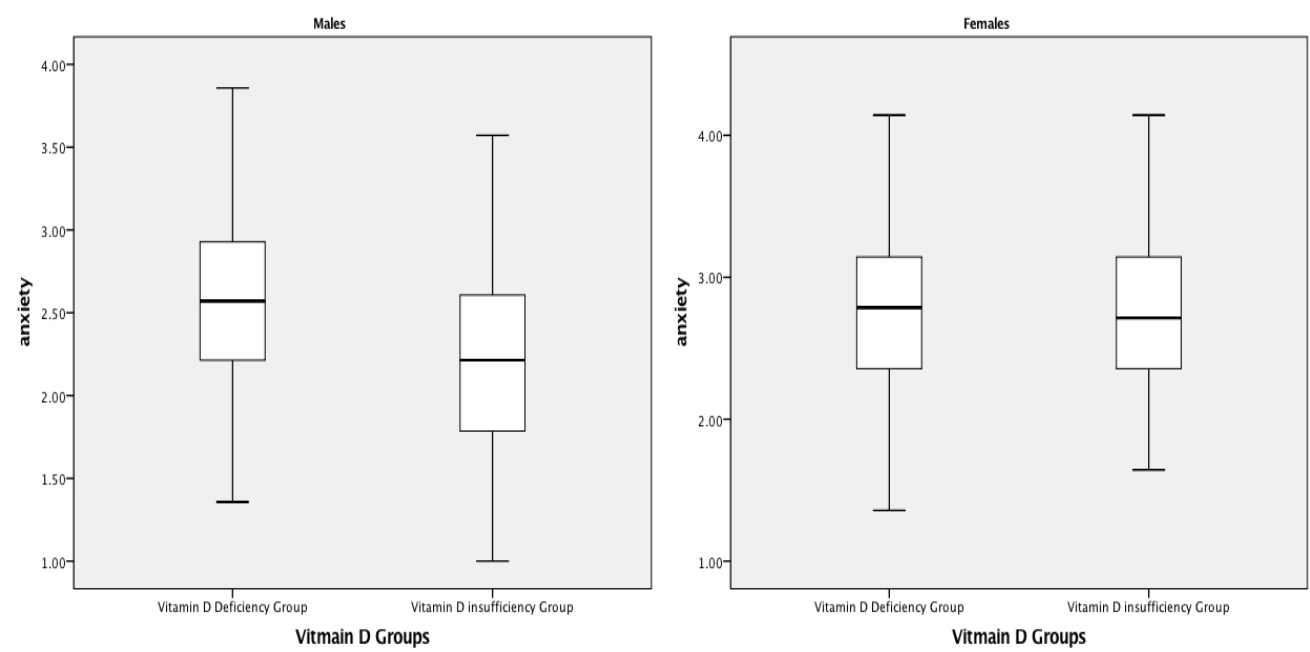

Figure 2: Shows boxplot of anxiety rates for Saudi males with vitamin D deficiency and insufficiency, and Saudi females with vitamin D deficiency and insufficiency

As can be seen from Figure 2, the anxiety median of Saudi males with vitamin $\mathrm{D}$ deficiency is 2.57 (the upper quartile is 2.93 , the lower quartile is 2.21); whereas the median of their peers with vitamin $\mathrm{D}$ insufficiency is 2.21 (the upper quartile is 2.64 , the lower quartile is 1.8). Regarding the opposite sex, the anxiety median of Saudi females with vitamin D deficiency is 2.78 (the upper quartile is 3.14 , the lower quartile is 2.28); while the median of their peers with vitamin D insufficiency is 2.71 (the upper quartile is 3.16, the lower quartile is 2.36).

\section{Discussion}

As can be seen from the above results all the females - from both vitamin D deficiency and insufficiency groups - show higher means in anxiety than their male peers. This may due to their gender especially given that it has been discussed in DSM-5 that anxiety occurs more frequently in females than in males: in an approximately 2:1 ratio (American Psychiatric Association, 2013). Similarly, Baxter et al. (2013) believe that women are more than twice as likely to suffer from anxiety disorder compared with men. However, this proportion might not be the same if the targeted sample is Saudis or other Arabs. Alansari (2006) conducted a survey study to explore the gender differences in anxiety among undergraduates in 16 Islamic countries, one of which was Saudi Arabia, and its sample was 630 students. He used the Kuwait University Anxiety Scale (KUAS) that measures cognitive/affective, behavioural/subjective, and somatic anxiety, and found that there was no significant difference in rates of this disorder 
between Saudi males and females, that is, their anxiety means were 37.11 and 37.21 respectively. This similarity in anxiety means might show that this disorder is a common psychological condition among Saudis regardless of their gender. This is in line with the current study's outcome that is there was no significant difference between anxiety scores for Saudi males and females with vitamin $\mathrm{D}$ deficiency, that is their anxiety means were 2.54 and 2.75 respectively. It would also be worthwhile to consider that anxiety in general and specific types of the disorder such as phobic anxiety and social anxiety disorder (also know as social phobia) are common anxiety disorders in Saudi Arabia. For example, Al Gelban (2009) found that $16.4 \%$ of Saudi secondary school girls have phobic anxiety, whereas other disorders such as depression, paranoid ideation, and interpersonal sensitivity were not represented in the same high percentages among the girls: they were $13.9 \%, 13.8 \%$ and $13.8 \%$ respectively. Regarding males, Ghazwani, Khalil, \& Ahmed (2016) found that $11.7 \%$ of Saudi adolescent boys suffer from social anxiety disorder, which is a high ratio especially when one compares it, for instance, with $6.2 \%$ in America (Kroenke et al., 2007). All these high anxieties prevalent among Saudis emphasises the importance of understanding that one of the underlying reasons for this disorder may be that they are suffering from low vitamin D levels.

In a national - Saudi - study conducted by Tuffaha et al. (2015), and approved by the Saudi Ministry of Health and its Institutional Review Board (IRB), the researchers aimed to investigate vitamin D status among Saudi adults (aged 15 and above) from all the 13 Saudi regions to represent the Saudi population. The sample comprised 10,735 participants, and the findings showed that $62.65 \%$ of Saudi females and $40.6 \%$ males were deficient/insufficient in vitamin D; i.e. their vitamin D levels were ranged 0$28 \mathrm{ng} / \mathrm{mL}$. Other studies have discussed a similar high prevalence of low vitamin D levels among Saudis. For instance, Sadat-Ali et al. (2009) found that between $28 \%$ to $37 \%$ of Saudi healthy men, in the eastern region of the country, suffered from vitamin D deficiency. In another example, Elsammak et al. (2011) found that more than $65 \%$ of Saudis in the eastern region were diagnosed with vitamin D deficiency. Hussain et al. (2014) is another study which targeted the population in Saudi Arabia, and found that $31.9 \%$ of their sample, 10,709 participants, suffered from low vitamin D levels (less than 25 $\mathrm{ng} / \mathrm{mL}$ ), noting that females made up the largest proportion of this prevalence. As can be seen from all these figures, vitamin D deficiency and insufficiency represent an epidemic in Saudi Arabia; and therefore, it is essential to find out the possible reasons for such a health condition in the country.

Bosomworth (2011) discussed possible risk factors that may lead to low vitamin D levels, such as: lack of sun exposure, traditional clothing, 
urbanisation, female gender, and limited dietary choices. Arguably, all these factors actually exist in Saudi Arabia. For instance, "Saudi Arabia is among the countries with the highest number of sunny days per year" (Tuffaha et al., 2015, p. 467), and in the last few years the Saudi weather records have documented extreme temperature indices which - for example - reached 52 ${ }^{\circ} \mathrm{C}$ on 22 June 2010 in Jeddah, the second largest city in the country (Almazroui et al., 2014, p. 808). Such temperature prevents people from being outdoors and getting the benefit of sunlight. The human body needs to be exposed to sunlight so it can synthesise vitamin $\mathrm{D}$, especially to ultraviolet B (UVB) (Cantorna et al., 2004; Green et al., 2015). Related to this are the traditional clothes. In Saudi Arabia women wear a fully covering black dress, known as an 'Abaya', and for some women this clothing style includes covering the face. Glerup et al. (2000) stated "black clothes exclude $100 \%$ UV-B" (p. 261). Saudi men also wear a traditional garment, known as a 'Thobe', which is a long white dress with long sleeves. This prevents the skin from being exposed to sunlight as well. Therefore, a number of studies have considered these - and similar - cultural concealing clothing styles, which exist in Saudi Arabia and other Islamic countries, as one of the direct factors of hypovitaminosis D. These include (Abokrysha, 2012; Al Attia \& Ibrahim, 2012; Christie \& Mason, 2011; El-Hajj Fuleihan, 2009; Elsammak et al., 2011; Tuffaha et al., 2015). Besides the clothing style and the extreme heat, there is also the problem of urbanisation in Saudi Arabia. Bosomworth (2011) discussed the fact that "increasing time indoors and increased automobile use ... [and] exercise indoors" (p. 17) are risk factors for low vitamin D levels.

All the factors discussed above are related to lack of sun exposure. However there are other aspects that cause, or raise the possibility of vitamin D deficiency: being a female, lack of dietary quality, and lack of consuming vitamin D supplements. Regarding gender, the demands of pregnancy would reduce vitamin D levels among women. This was clearly shown in Huang et al. (2014) when the researchers measured the vitamin levels in a sample of 498 pregnant women and found that the total serum of $25[\mathrm{OH}] \mathrm{D}(\mathrm{ng} / \mathrm{mL})$ was about 34.4 which may be considered low or near the lower boundary. In another study carried out by Boyle (2014), the researcher discussed that in some populations only $20 \%$ of pregnant women have the recommended level of the vitamin, while $50 \%$ are deficient. Concerning limited dairy choices, Sadat-Ali et al. (2013) aimed to investigate the status of fortified vitamin D content in commonly consumed food items in the Saudi market such as fresh and powdered milk, yoghurt, cheese, and orange juice. They found that these selected items of food mostly contained lower vitamin D amounts than that recommended by the US Code of Federal Regulations (ibid). For instance, the fresh milk from Al-Marai, which is a commonly used brand in Saudi 
Arabia, contains 400 IU/L of vitamin D; however, the US market regulation determines that fresh milk must contain $400 \mathrm{IU}$ for each quarter of a litre (ibid). This highlights the fact that individuals with vitamin $\mathrm{D}$ deficiency or insufficiency require large doses - more than 400 IU daily - to raise their 25(OH)D levels to normal (Bosomworth, 2011, p. 19). The last risk factor that may cause hypovitaminosis D among Saudis is their lack of using vitamin D supplements. Tuffaha et al. (2015) emphasise the fact that although more than $62 \%$ of Saudi females and more than $40 \%$ of males suffer from vitamin D deficiency/insufficiency, out of them, less than $1 \%$ of males and less than $2 \%$ of females use vitamin D supplements. Thus it can be seen that all these factors increase the possibility of having low vitamin $D$ levels among the Saudi population.

Based on all the discussion in this paper, there are two problems among Saudis: high rates of anxiety and vitamin D deficiency/insufficiency, which both exist among males and females even though these problems are more evidential among females. Therefore, further studies are required to investigate gender differences in rates of anxiety and vitamin D deficiency and insufficiency, and to investigate the rapidly growing rates of anxiety and low vitamin D levels. Additionally, this research suggests creating effective awareness methods to encourage Saudi people to benefit from vitamin D sources and supplements.

In conclusion, this study found that Saudis - both males and females - with vitamin D deficiency have a higher means in anxiety. The results show also that females from both groups - vitamin D deficiency and insufficiency - were higher in anxiety means than males. The significant differences occurred between anxiety scores for males and females with vitamin D insufficiency, and the magnitude of this difference was large. The second significant difference occurred between anxiety scores for males from both groups, vitamin D deficiency and insufficiency, and the magnitude of this difference was moderate. In addition, the results showed that the total anxiety mean was higher among Saudis with vitamin D deficiency than their peers in the insufficiency group. All these results are in line with previous studies that have discussed the high prevalence of anxiety among Saudis. This is also in line with the literature that has discussed the epidemic of vitamin D deficiency in Saudi Arabia and has emphasised the importance of finding a solution to the problem. Hence, this research suggests that more studies should be conducted to investigate the rapidly growing rates of both problems - anxiety and low vitamin D levels - among Saudis, and the differences between males and females in rates of anxiety and low levels of vitamin D; and also to create effective awareness methods to encourage the people of Saudi Arabia to benefit from vitamin D sources. 
This study is limited by the fact that it adopted a cross-sectional methodology, which prevents investigation of the causality between the two elements under study. The collected data about anxiety is based on a selfreport tool; i.e. a questionnaire. The non-probability sample is not representative of the Saudi population especially because the participants who agreed to take part in this study were only from Riyadh, the capital.

\section{References:}

Abokrysha, N. T. (2012). Vitamin D deficiency in women with fibromyalgia in Saudi Arabia. Pain Medicine, 13(3), 452-458. doi:10.1111/j.15264637.2011.01304.x.

Al Attia, H. M., \& Ibrahim, M. A. (2012). The high prevalence of vitamin D inadequacy and dress style of women in the sunny UAE. Archives of Osteoporosis, 7(1), 307-310. doi:10.1007/s11657-012-0104-1.

Al Gelban, K. S. (2009). Prevalence of psychological symptoms in Saudi secondary school girls in Abha, Saudi Arabia. Annals of Saudi Medicine, 29(4), 275-279. doi:10.4103/0256-4947.55308.

Al Hariri, A. (2016). Vitamin D deficiency and insufficiency and their role in growing levels of depression and anxiety in Saudi Arabia. Journal of Psychiatry, 19(3). doi:10.4172/2378-5756.1000360

Al Khatib, A. J., \& Rawashdeh, W. S. (2014). The relationship between vitamin D deficiency with depression and addiction. European Scientific Journal, 10(24), 131-142.

Al-Gelban, K. S., Al-Amri, H. S., \& Mostafa, O. A. (2009). Prevalence of depression, anxiety and stress as measured by the Depression, Anxiety, and Stress Scale (DASS-42) among secondary school girls in Abha, Saudi Arabia. Sultan Qaboos University medical journal, 9(2), 140-147.

Alansari, B. M. (2006). Gender differences in anxiety among undergraduates from sixteen Islamic countries. Social Behavior \& Personality: An international Journal, 34(6), 651-659.

Almazroui, M., Islam, M. N., Dambul, R., \& Jones, P. D. (2014). Trends of temperature extremes in Saudi Arabia. International Journal of Climatology, 34(3), 808-826. doi:10.1002/joc.3722.

American Psychiatric Association. (2013). Diagnostic and statistical manual of mental disorders (5th ed.). Washington, DC: American Psychiatric Association.

Amr, M., Amin, T., \& El-Wasify, M. (2012). P-468 - Prevalence and correlates of depression and anxiety among high school students in eastern region, saudi arabia. European Psychiatry, 27(1), 1. doi:10.1016/S09249338(12)74635-7. 
Baxter, A. J., Scott, K. M., Vos, T., \& Whiteford, H. A. (2013). Global prevalence of anxiety disorders: a systematic review and meta-regression. Psychological Medicine, 43(5), 897-910. doi:10.1017/S003329171200147X. Bischoff-Ferrari, H. A. (2007). The 25-hydroxyvitamin D threshold for better health. Journal of Steroid Biochemistry and Molecular Biology, 103(3), 614-619. doi:10.1016/j.jsbmb.2006.12.016.

Bosomworth, N. J. (2011). Mitigating epidemic vitamin D deficiency: The agony of evidence. Canadian Family Physician, 57, 16-20.

Boyle, V. (2014). Vitamin D and pregnancy. Obstetrics, Gynaecology \& Reproductive Medicine, 24(10), 315-316. doi:10.1016/j.ogrm.2014.07.005.

Bryman, A. (2012). Social research methods (4th ed.). Oxford: Oxford University Press.

Cantorna, M. T., Zhu, Y., Froicu, M., \& Wittke, A. (2004). Vitamin D status, 1,25-dihydroxyvitamin D3, and the immune system. The American journal of clinical nutrition, 80(6), 1717-1720.

Christie, F. T. E., \& Mason, L. (2011). Knowledge, attitude and practice regarding vitamin D deficiency among female students in Saudi Arabia: A qualitative exploration. International Journal of Rheumatic Diseases, 14(3), e22-e29. doi:10.1111/j.1756-185X.2011.01624.x.

Cook, C., Heath, F., \& Thompson, R. L. (2000). A meta-analysis of response rates in web- or internet-based surveys. Educational and Psychological Measurement, 60(6), 821-836. doi:10.1177/00131640021970934

Craske, M. G., \& Stein, M. B. (2016). Anxiety. The Lancet, 1-12. doi:10.1016/S0140-6736(16)30381-6.

El-Hajj Fuleihan, G. (2009). Vitamin D deficiency in the Middle East and its health consequences for children and adults. Clinical Reviews in Bone and Mineral Metabolism, 7(1), 77-93. doi:10.1007/s12018-009-9027-9.

Elsammak, M. Y., Al-Wossaibi, A. A., Al-Howeish, A., \& Alsaeed, J. (2011). High prevalence of vitamin D deficiency in the sunny Eastern region of Saudi Arabia: a hospital-based study. Eastern Mediterranean health journal, 17(4), 317-322.

Faiz, S., Panunti, B., \& Andrews, S. (2007). The epidemic of vitamin D deficiency. The Journal of the Louisiana State Medical Society : official organ of the Louisiana State Medical Society, 159(1), 17-20. Retrieved from http://citeseerx.ist.psu.edu/viewdoc/download?doi=10.1.1.511.9522\&rep=re p1\&type=pdf.

Ghazwani, J. Y., Khalil, S. N., \& Ahmed, R. A. (2016). Social anxiety disorder in Saudi adolescent boys: Prevalence, subtypes, and parenting style as a risk factor. Journal of Family \& Community Medicine, 23(1), 25-31. doi:10.4103/2230-8229.172226.

Glerup, H., Mikkelsen, K., Poulsen, L., Hass, E., Overbeck, S., Thomsen, J., Charles, P., \& Eriksen, E. F. (2000). Commonly recommended daily intake 
of vitamin D is not sufficient if sunlight exposure is limited. Journal of Internal Medicine, 247(2), 260-268. doi:10.1046/j.1365-2796.2000.00595.x. Goldstein, D. (2009). The epidemic of vitamin D deficiency. Journal of Pediatric Nursing, 24(4), 345-346. doi:10.1016/j.pedn.2009.05.005.

Green, R. J., Edris, A., Salah, M., Samy, G., Miqdady, M. S., El-Hodhod, M., Akinyinka, O. O., Saleh, G., Haddad, J., Alsaedi, S. A., \& Mersal, A. Y. (2015). Vitamin D deficiency and insufficiency in Africa and the Middle East, despite year-round sunny days. Samj South African Medical Journal, 105(7), 603-605. doi:10.7196/SAMJnew.7785.

Holick, M. F. (2005). Vitamin D: Important for preention of osteoporosis, cardiovascular heart disease, type 1 diabetes, autoimmune diseases, and some cancers. Southern Medical Journal, 98(10), 1024-1027.

Holick, M. F. (2006a). High prevalence of vitamin D inadequacy and implications for health. Mayo Clinic proceedings, 81(3), 353-373. Retrieved from http://dx.doi.org/10.4065/81.3.353.

Holick, M. F. (2006b). Resurrection of vitamin D deficiency and rickets. The Journal of Clinical Investigation, 116(8), 2062-2072. doi:10.1172/JCI29449

Holick, M. F. (2007). Vitamin D deficiency. The New England Journal of Medicine, 357(3), 266-281. doi:10.1056/NEJMra070553.

Howland, R. H. (2011). Vitamin D and depression. Journal of Psychosocial Nursing and Mental Health Services, 49(2), 15-18. doi:10.3928/0279369520110111-02.

Huang, J. Y., Arnold, D., Qiu, C.-F., Miller, R. S., Williams, M. A., \& Enquobahrie, D. A. (2014). Association of serum vitamin D with symptoms of depression and anxiety in early pregnancy. Journal of Women's Health, 23(7), 588-595. doi:10.1089/jwh.2013.4598.

Humble, M. B. (2010). Vitamin D, light and mental health. Journal of

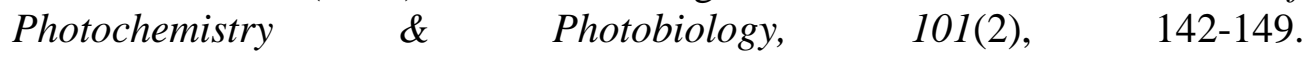
doi:10.1016/j.jphotobiol.2010.08.003.

Hussain, A. N., Alkhenizan, A. H., El Shaker, M., Raef, H., \& Gabr, A. (2014). Increasing trends and significance of hypovitaminosis D: a population-based study in the Kingdom of Saudi Arabia. Archives of Osteoporosis, 9(1), 1-5. doi:10.1007/s11657-014-0190-3.

Ibrahim, N., Al-Kharboush, D., El-Khatib, L., Al-Habib, A., \& Asali, D. (2013). Prevalence and predictors of anxiety and depression among female medical students in King Abdulaziz University, Jeddah, Saudi Arabia. Iranian Journal of Public Health, 42(7), 726-736. Retrieved from http://www.ncbi.nlm.nih.gov/pmc/articles/PMC3881618/.

Johnson, L. K., Hofsø, D., Aasheim, E. T., Tanbo, T., Holven, K. B., Andersen, L. F., Røislien, J., \& Hjelmesæth, J. (2012). Impact of gender on vitamin $\mathrm{D}$ deficiency in morbidly obese patients: A cross-sectional study. 
European Journal of Clinical Nutrition, 66(1), 83-90. doi:10.1038/ejen.2011.140.

Kim, C. S., \& Kim, S. W. (2014). Vitamin D and chronic kidney disease. The Korean Journal of Internal Medicine, 29(4), 416-427. doi:10.3904/kjim.2014.29.4.416.

Kroenke, K., Spitzer, R. L., Williams, J. B. W., Monahan, P. O., \& Löwe, B. (2007). Anxiety disorders in primary care: prevalence, impairment, comorbidity, and detection. Annals of Internal Medicine, 146(5), 317-325. doi:10.7326/0003-4819-146-5-200703060-00004.

Lašaite, L., Gailyte, I., Puzinas, P., Preikša, R. T., \& Kazanavičius, G. (2011). Vitamin D deficiency is related to worse emotional state. Central European Journal of Medicine, 6(5), 558-566. doi:10.2478/s11536-0110061-x.

Modan-Moses, D., Levy-Shraga, Y., Pinhas-Hamiel, O., Kochavi, B., EnochLevy, A., Vered, I., \& Stein, D. (2015). High prevalence of vitamin D deficiency and insufficiency in adolescent inpatients diagnosed with eating disorders. International Journal of Eating Disorders, 48(6), 607-614. doi:10.1002/eat.22347.

Nulty, D. D. (2008). The adequacy of response rates to online and paper surveys: What can be done? Assessment \& Evaluation in Higher Education, 33(3), 301-314. doi:10.1080/02602930701293231

Qureshi, N. A., Al-Habeeb, T. A., Al-Ghamdy, Y. S., Magzoub, M. E., \& Van der Molen, H. T. (2001). Psychiatric co-morbidity in primary care and hospital referrals, Saudi Arabia. Eastern Mediterranean health journal, 7(3), 492-501.

Robson, C. (2011). Real world research (3rd ed.). Sussex: Wiley.

Sadat-Ali, M., Al Elq, A., Al-Farhan, M., \& Sadat, N. A. (2013). Fortification with vitamin D: Comparative study in the Saudi Arabian and US markets. Journal of Family and Community Medicine, 20(1), 49-52. doi:10.4103/2230-8229.108186.

Sadat-Ali, M., Alelq, A., Al-Turki, H., Al-Mulhim, F., \& Al-Ali, A. (2009). Vitamin D levels in healthy men in eastern Saudi Arabia. Annals of Saudi Medicine, 29(5), 378-382. Retrieved from http://www.ncbi.nlm.nih.gov/pubmed/19700896.

Shelby, L. B. (2011). Beyond Cronbach's alpha: Considering confirmatory factor analysis and segmentation. Human Dimensions of Wildlife, 16(2), 142148. doi:10.1080/10871209.2011.537302.

Tuffaha, M., Al Rabeeah, A. A., Mokdad, A. H., El Bcheraoui, C., Daoud, F., Al Hussaini, H. A., Alamri, F., Al Saeedi, M., Basulaiman, M., Memish, Z. A., \& AlMazroa, M. A. (2015). Deficiencies under plenty of sun: Vitamin D status among adults in the Kingdom of Saudi Arabia, 2013. North 
American journal of medical sciences, 7(10), 467-475. doi:10.4103/19472714.168675.

Whiting, S. J., \& Calvo, M. S. (2005). Dietary recommendations for vitamin D: A critical need for functional end

points to establish an estimated average requirement. The Journal of Nutrition, 135(2), 304-309.

World Health Organization. (1992). ICD-10 Classifications of Mental and Behavioural Disorder: Clinical Descriptions and Diagnostic Guidelines. Geneva: World Health Organisation. 